Article

\title{
Design and Field Tests of an Inverted Based Remote MicroGrid on a Korean Island
}

\author{
Woo-Kyu Chae ${ }^{1}$, Hak-Ju Lee ${ }^{1}$, Jong-Nam Won ${ }^{1}$, Jung-Sung Park ${ }^{1}$ and Jae-Eon Kim ${ }^{2, *}$ \\ 1 Research Institute, Korea Electric Power Corporation, Daejeon 305-760, Korea; \\ E-Mails:wkchae@kepco.co.kr (W.-K.C.); juree@kepco.co.kr (H.-J.L.); \\ jnwon@kepco.co.kr (J.-N.W.); jindulpa@kepco.co.kr (J.-S.P.) \\ 2 School of Electrical Engineering, Chungbuk National University, Chungbuk 361-763, Korea \\ * Author to whom correspondence should be addressed; E-Mail: jekim@cbnu.ac.kr; \\ Tel.: +82-432-612-423; Fax: +82-432-632-419.
}

Academic Editor: William Holderbaum

Received: 14 May 2015 / Accepted: 27 July 2015 / Published: 5 August 2015

\begin{abstract}
In this paper, we present the results of an economic feasibility study and propose a system structure to test and maintain electrical stability. In addition, we present real operation results after constructing a remote microgrid on an island in South Korea. To perform the economic feasibility study, a commercial tool called HOMER was used. The developed remote microgrid consists of a $400 \mathrm{~kW}$ wind turbine (WT) generator, $314 \mathrm{~kW}$ photovoltaic $(\mathrm{PV})$ generator, $500 \mathrm{kVA} \times 2$ grid forming inverter, $3 \mathrm{MWh}$ lithium ion battery, and an energy management system (EMS). The predicted renewable energy fraction was $91 \%$ and real operation result was $82 \%$. The frequency maintaining rate of the diesel power plants was $57 \%$ but the remote microgrid was $100 \%$. To improve the operating efficiency of the remote microgrid, we investigated the output range of a diesel generator.
\end{abstract}

Keywords: microgrid; wind turbine; remote; island; hybrid power system; battery; HOMER; feasibility study

\section{Introduction}

Power supply in isolated regions far from land, including islands, is typically provided by small capacity diesel power plants. To overcome the high cost of diesel fuel in these small-capacity electrical 
power systems, and to prevent environmental pollution, a hybrid power system has begun to be applied, including in Alaska (USA). A hybrid power system is a diesel power plant system interconnected with a wind-turbine generator (WT) and photovoltaic (PV) array [1]. However, a restriction on renewable energy capacity that can be interconnected with a diesel power plant is still applied on account of the output variances of WTs and PVs. An attempt has been made to add a large capacity battery to the hybrid power system to solve the above problem owing to the sharp decline in battery prices in recent years. Such a system is called a remote microgrid (Figure 1) or hybrid microgrid [2-5]. However, renewable energy or batteries remain expensive, therefore, it is necessary to have an appropriate combination to construct an economically feasible system.

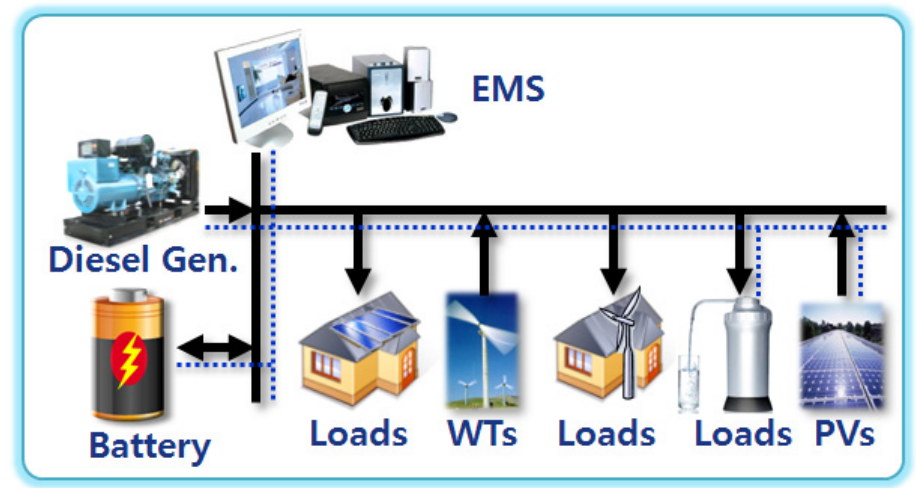

Figure 1. Example of a remote microgrid.

To effectively utilize the renewable energy cost, many researchers have studied algorithms to calculate the capacity of applicable generator units that can constitute a low cost reliable power system [6]. Li et al. [6] compared some proposed algorithms and presented a simple algorithm to determine the required number of generating units of a WT generator and PV array, as well as the associated storage capacity for a standalone hybrid microgrid. The algorithm is based on the observation that the battery charge state should be periodically invariant. Liang et al. [7] investigated the stochastic modeling and optimization tools for microgrids. Wang et al. [8] proposed an optimal capacity allocation method for standalone microgrids using a particle swarm optimization algorithm. Bansal et al. [9] analyzed the economic feasibility of a hybrid power system using the biogeography-based optimization (BBO) algorithm. Wies et al. [10] modeled load sharing between a diesel generator and PV using Simulink and presented how to analyze the economic feasibility. Xu et al. [11] proposed an optimal sizing method to achieve higher power supply reliability. However, Stiel et al. [12] and Yoo et al. [13] used a commercial feasibility study tool called HOMER instead of complex algorithms and thereby presented economic feasibility assessments results on a wind-diesel hybrid power system.

Purser et al. [14] presented the results of a technical and economic feasibility study of implementing a microgrid at Georgia Southern University using HOMER. Mizani et al. [15] presented the demonstration results for optimal design and operation of a grid-connected microgrid.

Fan et al. [16] presented design considerations to develop a standalone smart grid on Ubin Island (Pulau) as well as simulation results. Kojima et al. [17] proposed a structure and control method of an existing diesel power plant interconnected with a small capacity of WT, PV, and batteries. Prull et al. [18] proposed a design procedure, including a load study and meteorological information study, as well as 
design results to construct a remote microgrid on Necker Island (UK), but they didn't include any field test results. Fay et al. [1] presented the performance and economic analysis results for isolated wind-diesel systems in Alaska. Kaldellis et al. [19] presented cost-benefit analysis results of remote hybrid wind-diesel power stations. Ulleberg et al. [20] presented a remote renewable energy system for the Faroe Islands, but these wind-diesel systems usually didn't include the battery and/or photovoltaic generator. However, some studies presented algorithms that use only partial information to quickly calculate renewable energy and battery capacity. In particular, such algorithms do not consider the charge and discharge efficiency of the battery system and the depth of discharge (DoD) according to battery type. Some algorithms were only theoretically validated. Although some of the above studies proposed a design procedure for a remote microgrid, they provided no operational results from real sites. Some studies presented the comparison results between simulation and real implementation but they usually didn't include the design targets such like raising the system efficiency, stable operation, power quality, etc. To construct a remote microgrid, it is necessary to have an optimal system design that considers the power reserve ratio to both ensure the system economic feasibility and maintain the stable operation and rated voltage and frequency of the system. In addition to the above considerations, an appropriate system structure should be considered. The system should be constructed according to the design results; moreover, the design procedure should be validated and fed back through comparisons with long-term operation results. However, no studies have provided such a series of procedures.

The present paper presents economic feasibility study results and a system structure to develop a grid-forming inverter-based remote microgrid for distant islands located on the west coast of South Korea. It presents design parameters for economical and reliable remote microgrid designs through comparisons between simulation results and real operation results. Moreover, this study aims to share the optimal design direction through real long-term operation results of the remote microgrid.

\section{Isolated Power System}

\subsection{Penetration Level of Renewable Energy}

When incorporating renewable-based technologies into isolated power systems, the amount of energy that will be obtained from the renewable sources will strongly influence the technical layout, performance and economics of the system. For this reason, it is necessary to explain two new parameters - the instantaneous and average power penetration of wind - as they help define system performance [21].

The average and peak penetration of renewable generation in a hybrid power system can be defined as shown in Equations (1) and (2) [18]:

$$
\begin{aligned}
& \text { Average Penetration }=\frac{\text { Energy from Renewable Generation }(\mathrm{kWh})}{\text { Electrical Load }(\mathrm{kWh})} \\
& \text { Peak Penetration }=\frac{\text { Peak Power from Renewable Generation }(\mathrm{kW})}{\text { Electrical Load }(\mathrm{kW})}
\end{aligned}
$$

In [22], these definitions are used to categorize hybrid power systems into three classes: low, medium and high penetration, as shown for reference in Table 1. 
Table 1. Hybrid power system penetration classifications.

\begin{tabular}{ccc}
\hline System Class & Peak Penetration & Annual Average Penetration \\
\hline Low & $<50 \%$ & $<20 \%$ \\
Medium & $50 \%-100 \%$ & $20 \%-50 \%$ \\
High & $100 \%-400 \%$ & $>50 \%$ \\
\hline
\end{tabular}

\subsection{Hybrid Power System}

The electric power production cost for diesel power plants located in islands or remote areas - depending on their scale and distance from land - can be up to 10 times higher that of the large-scale electrical power systems [23]. To reduce the electric power production cost, renewable energy systems such as wind turbine generators or photovoltaic generators are sometimes installed in parallel with the diesel power plant. This kind of system is called a hybrid power system [22]. Depending on its structure and the portion of renewable energy in the whole system, the diesel generators of the hybrid power system should maintain their voltage and frequency most of the time.

\subsection{Inverter-Based Remote MicroGrid}

Whereas the hybrid power system controls the voltage and frequency through its diesel generator, a remote microgrid has its Grid Forming Inverter (GFI) and individual distributed generators contribute to voltage/frequency control [18]. GFI maintains the system voltage/frequency through charging the battery if there is excess energy and vice versa. Coordination between GFI and WT is critical for stability performance. Using a large capacity GFI, a remote microgrid can usually utilize more renewable energy than a hybrid power system because a GFI can very quickly absorb the excess energy from the renewable energy using the battery [24].

\section{Feasibility Study for Test Island}

The remote microgrid referenced in this paper was designed to minimize power supply costs through an optimal combination of distributed power and the energy storage devices, and to consider reliable operations. In this section, the economic feasibility study results of the proposed remote microgrid are presented using HOMER. The economic feasibility study used real meteorological and load data from the actual site.

\subsection{Feasibility Study Tool}

To economically construct a remote microgrid, renewable energy type, battery type, and capacity should be accurately calculated. In addition, precise analysis of target area meteorological data is likewise needed. Such a series of processes is called a feasibility study, which can be performed by the most widely used commercial tool called HOMER.

HOMER is a computer simulation program designed by the National Renewable Energy Laboratory (NREL) in the United States. Coined as the Optimization Model for Distributed Power, HOMER allows the modelling of both grid and non-grid connected power systems consisting of conventional and renewable technologies. The program considers the economic and technical feasibility of desired 
power systems and delivers comprehensive reports covering a range of subjects from the net present capital cost of the system to the renewable penetration. It allows the input of renewable resources such as wind speeds, battery data, demand load data, capital and operation and maintenance (O\&M) costs among others, as well as sensitivity analyses modelling the impact on the system to variations in any input [25].

HOMER uses the following equation to calculate the total net present cost:

$$
C_{N P C}=\frac{C_{a n n, t o t}}{C R F\left(i, R_{\text {proj }}\right)}
$$

where $C_{a n n, t o t}$ is the total annualized cost, $i$ the annual real interest rate (the discount rate), $R_{\text {proj }}$ the project lifetime, and CRF (discount raterecovery factor), given by Equation (4):

$$
\operatorname{CRF}(i, N)=\frac{i(1+i)^{N}}{(1+i)^{N}-1}
$$

where $i$ is the annual real interest rate and $N$ is the number of years.

HOMER uses the following equation to calculate the levelized cost of energy:

$$
C O E=\frac{C_{\text {ann }, \text { tot }}}{E_{\text {prim }}+E_{\text {def }}+E_{\text {grid,sales }}}
$$

where $C_{a n n, t o t}$ is the total annualized cost, $E_{\text {prim }}$ and $E_{d e f}$ are the total amounts of primary and deferrable load, respectively, that the system serves per year, and $E_{\text {grid,sales }}$ is the amount of energy sold to the grid per year [25].

\subsection{Test Island in Korea}

A distant target island was selected to validate the remote microgrid technology. Table 2 shows the information about the target island. The target island is located approximately $6 \mathrm{~km}$ from the mainland and currently has approximately 280 residents. There are three $100 \mathrm{~kW}$ diesel generators on the island; two generators operate in parallel during normal hours and one is for reserve. The distributed voltage is $6.6 \mathrm{kV}$, and there are two distribution lines. The heavy load supplied to the diesel power plant during normal operation hours is produced by an induction motor whose rated capacity is $11 \mathrm{~kW}$. The mean wind velocity and solar radiation in 2013 were $5.1 \mathrm{~m} / \mathrm{s}$ and $3.68 \mathrm{kWh} / \mathrm{m}^{2}$.day, respectively, which represent typical data in offshore islands in South Korea [26].

Table 2. Overview of the Test Island [27].

\begin{tabular}{cc}
\hline Name & Gasado (Gasa Island) \\
Location & Southern part of South Korea \\
Area & $6.4 \mathrm{~km}^{2}$ \\
Population & 286 person $(168$ house $)$ \\
Electrical System & Gen-set: $100 \mathrm{~kW} \times 3(1992$ year); Distribution Line $(6.6 \mathrm{kV}): 8 \mathrm{~km} ;$ \\
Fuel Consumption & Main Transformer $(380 \mathrm{~V} / 6.9 \mathrm{kV}): 300 \mathrm{kVA} \times 2$ \\
Load (2013year) & $285,000 \mathrm{~L} / \mathrm{year}(2013$ year $)$ \\
& Average: $113 \mathrm{~kW}$; Peak: $210 \mathrm{~kW}$; Minimum: $50 \mathrm{~kW} ;$ \\
Weather (Annual average) & Heavy load: $11 \mathrm{~kW} ;$ Induction Motor $\times 2$ \\
\hline
\end{tabular}




\subsection{Results of Economic Feasibility Study}

The data presented in Section 3.2 and the Appendix were entered into HOMER to run the economic feasibility study simulation The simulation input data were set with consideration of the current diesel power plant operation results and current prices of renewable energy and batteries to be as realistic as possible.

The simulation results of the target island are summarized in Table 3, which shows a typical combination according to the renewable energy fraction. As shown in the table, the Cost of Energy (COE) of the diesel power plant in the target island was $\$ 0.992$ and the annual operating cost was $\$ 869,000$. The operation cost consisted of the diesel generator fuel cost, maintenance cost for the power generator and lines, personnel cost for operators, and other expenses. Power bills paid by customers were omitted.

Table 3. Simulation result for economic feasibility study.

\begin{tabular}{|c|c|c|c|c|c|c|c|c|c|}
\hline $\begin{array}{c}\text { Ren. } \\
\text { Fraction } \\
(\%)\end{array}$ & $\begin{array}{l}\text { COE } \\
(\$)\end{array}$ & $\begin{array}{c}\text { NPC } \\
(1000 \$)\end{array}$ & $\begin{array}{c}\text { Operat. } \\
\text { Cost } \\
(1000 \$)\end{array}$ & $\begin{array}{c}\text { Initial } \\
\text { Capital } \\
(1000 \$)\end{array}$ & $\begin{array}{l}\text { Fuel } \\
\text { (kL) }\end{array}$ & $\begin{array}{c}\text { Photovoltaic } \\
(\mathbf{k W})\end{array}$ & $\begin{array}{c}\text { Wind } \\
\text { Turbine } \\
(100 \mathrm{~kW})\end{array}$ & $\begin{array}{c}\text { Battery } \\
(100 \mathrm{kWh})\end{array}$ & $\begin{array}{c}\text { Inverter } \\
(\mathrm{kVA})\end{array}$ \\
\hline 0 & 0.913 & 11,258 & 903 & 0 & 311 & 0 & 0 & 0 & 0 \\
\hline 10.9 & 0.833 & 10,277 & 735 & 1120 & 244 & 150 & 0 & 5 & 500 \\
\hline 20.9 & 0.822 & 10,134 & 698 & 1435 & 217 & 250 & 0 & 5 & 500 \\
\hline 30.8 & 0.834 & 10,285 & 671 & 1920 & 190 & 50 & 2 & 5 & 500 \\
\hline 40.9 & 0.875 & 10,794 & 693 & 2160 & 177 & 300 & 1 & 5 & 500 \\
\hline 50.5 & 0.879 & 10,849 & 653 & 2710 & 149 & 300 & 2 & 5 & 500 \\
\hline 59.7 & 0.885 & 10,916 & 622 & 3165 & 121 & 350 & 2 & 10 & 500 \\
\hline 69.8 & 0.901 & 11,111 & 587 & 3800 & 91 & 450 & 2 & 15 & 500 \\
\hline 80.9 & 0.919 & 11,342 & 546 & 4540 & 57 & 600 & 2 & 20 & 500 \\
\hline 89.9 & 1.051 & 12,963 & 553 & 6067 & 34 & 600 & 3 & 35 & 500 \\
\hline 94.4 & 1.284 & 15,835 & 575 & 8668 & 18 & 600 & 6 & 50 & 500 \\
\hline
\end{tabular}

Notes: Ren. Fraction: Renewable Fraction, COE: Cost of Energy, NPC: Net Present Cost, Operat. Cost: Operating Cost per Year.

The most economical system configuration can be formed with approximately $20 \%$ of renewable energy. However, the COE was lower or similar compared to that of the existing diesel power plant until a proportion of renewable energy in the remote microgrid reached approximately $70 \%$. Furthermore, under the same COE, various combinations of capacities of renewable energy and batteries can be possible.

\section{Remote Microgrid System Design}

In this section, the design objectives for achieving the implementation and demonstration of an energy independent island using remote microgrid technology, as well as the results, are presented.

\subsection{Design Target}

Table 4 shows the design target and results for the test island. The energy independence of the test island was set to $99 \%$, which means that $100 \%$ energy independence would not be pursued in 
consideration of the economic feasibility. That is, if required, diesel generators would be partially used. The daily average load in the test island was $113 \mathrm{~kW}$. However, an average load was set to $120 \mathrm{~kW}$ to account for the supply-ready loads and future load increase rate. The required renewable energy capacity could be calculated as shown in Equation 6. The result is consistent with that in Table 3.

Table 4. Design target and design results for the test island [26].

\begin{tabular}{|c|c|c|}
\hline Category & Design Target & Results \\
\hline $\begin{array}{l}\text { Renewable Energy } \\
\text { Fraction }\end{array}$ & $99 \%$ of power supplied by renewable energy & $\begin{array}{l}\text { wind turbine (WT): } 400 \mathrm{~kW} \text {; } \\
\text { photovoltaic (PV): } 314 \mathrm{~kW}\end{array}$ \\
\hline Battery Capacity & Power supply by batteries only for one or more days & $3 \mathrm{MWh}$ \\
\hline Inverter Capacity & $\begin{array}{l}\text {-Total recharge of renewable energy output; } \\
\text {-Inverter operation efficiency improvement }\end{array}$ & $\begin{array}{l}500 \mathrm{kVA} \times 2 \mathrm{ea}, 250 \mathrm{kVA} \times 1 \mathrm{ea} ; \\
\text { If } \mathrm{CVCF} \text { inverter capacity is not sufficient, } \\
\text { parallel inverter is running }\end{array}$ \\
\hline & -Parallel operation of inverters and diesel generators; & -Inverter: CVCF (Constant Voltage \\
\hline System optimization & $\begin{array}{l}\text {-Improvement of heat efficiency by fixed-speed } \\
\text { operation of the diesel generator }\end{array}$ & $\begin{array}{l}\text { Constant Frequency) operation; } \\
\text {-Diesel generator : Droop operation }\end{array}$ \\
\hline Electrical System & $\begin{array}{l}\text {-Microgrid technology validation; } \\
\text {-Commercial operation and cost minimization }\end{array}$ & $\begin{array}{l}\text {-Construction of new distribution line; } \\
\text {-Parallel interconnection with the main } \\
\text { transformer }\end{array}$ \\
\hline $\begin{array}{c}\text { EMS (Energy } \\
\text { Management System) }\end{array}$ & $\begin{array}{l}\text {-Overall monitoring and control of the system; } \\
\text {-System automatic operation }\end{array}$ & $\begin{array}{l}\text {-SCADA + application; } \\
\text {-Prediction of loads and renewable energy; } \\
\text {-Direct load control }\end{array}$ \\
\hline
\end{tabular}

According to the renewable energy capacity, $400 \mathrm{~kW}$ of WT and $314 \mathrm{~kW}$ of PV were installed with comprehensive consideration of the geographical characteristics, installation site, and building permit issues. A design goal was to set the power supply for only one day with batteries when no renewable energy output was supplied to achieve an energy independent island. This was calculated with Equation (7). Additional Depth of Discharge (DoD) was not considered because we selected lithium batteries:

Capacity of Renewable Energy $=$ Daily Average Load $\div$ Average Capacity Factor of Renewable Energy $=120 \mathrm{~kW} \div 17 \%=706 \mathrm{~kW}$

Capacity of Battery $=120 \mathrm{~kW}($ Daily Average Load $) \times 24 \mathrm{~h}=2880 \mathrm{kWh}$

Finally, we set the size of battery as $3 \mathrm{MWh}$ considering the $5 \%$ margin.

The inverter capacity was calculated via Equation (8) in consideration of the maximum renewable energy output:

$$
\begin{gathered}
\text { Capacity of Inverter }=\text { Maximum Output of Renewable Energy }- \text { Minimum Load } \\
\qquad 706 \mathrm{~kW}-60 \mathrm{~kW}=646 \mathrm{~kW}
\end{gathered}
$$

To account for a possible commercial inverter purchase and inverter operation efficiency, two 500-kVA inverters and one 250-kVA inverter were set up. One 500-kVA inverter was used for backup. A 250-kVA inverter was set in the "off" state during normal hours and was automatically turned on if renewable energy output exceeded the threshold value. Through this, we can raise the operation efficiency of the system. The inverters could be charged and discharged bi-directionally for system 
optimization and could be run with the diesel generators in parallel. To employ the existing facilities in their current states, the diesel generator was operated using the droop method.

To validate the microgrid technology prior to the commercial operation, a test distribution line $(\mathrm{D} / \mathrm{L})$ was installed. Using the test $\mathrm{D} / \mathrm{L}$ and main transformer for backup, the additional test system could be operated without power interruption. GFIs and the diesel generators are interconnected into the low voltage side of the main transformers to minimize the construction cost.

The overall system was monitored and controlled via an energy management system (EMS). To improve system efficiency, battery life management and diesel generator output were controlled using the prediction of loads and renewable energy power generation. For example, if the EMS predicts that the renewable energy supply will be enough within $24 \mathrm{~h}$, the EMS calculates the output power and the stop time of the diesel generators.

\subsection{Simulation Result for Test Island}

Renewable energy and battery capacities determined by the design target were entered into HOMER to run the simulation of annual power production and loss. The results are shown in Figure 2 and Table 5. It was estimated that the PV produced 354,156 kWh per year, the WT produced 759,718 $\mathrm{kWh}$ per year, and the diesel power generator produced $180,137 \mathrm{kWh}$ per year. A capacity factor of the PV was estimated less than that of other PV stations in South Korea, which was because the target area was an island. Although an energy independent island was designed as a goal, the renewal energy produced only $79.4 \%$ of the power required under the current construction conditions. Thus, the remainder of the power (20.6\%) should be supplied by the diesel generator. Excess power supplied by the renewable energy was estimated as $379,987 \mathrm{kWh} /$ year, which amounted to $29.4 \%$ of the total power production. This result was obtained because wind in South Korea is concentrated in the winter season on account of its geographical characteristic.

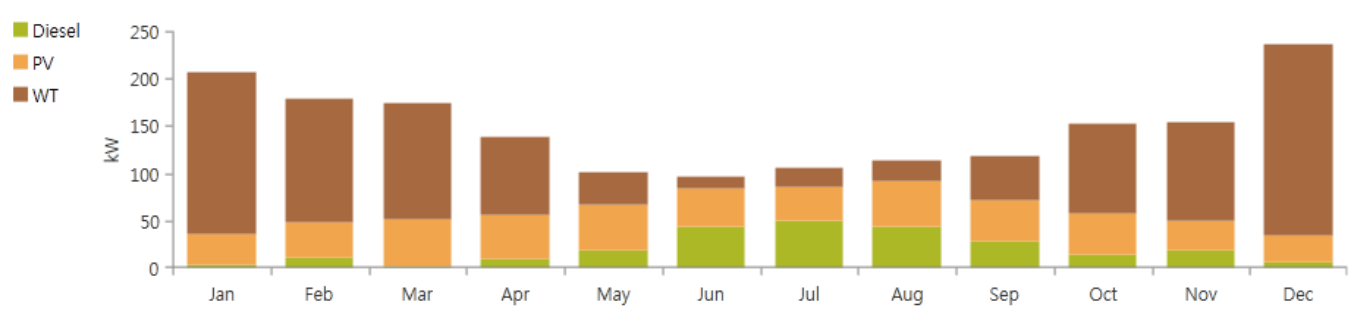

Figure 2. Expected monthly energy production by generator of the test island.

\section{Results and Discussion}

In this section, the result of a real remote microgrid construction in the test island and its operation results are presented. The results are compared with the simulation results in Section 3.2.

\subsection{Implementation Results of the Field Test Site}

Remote microgrid system was constructed on the test island in accordance with the design targets (Section 3.1). The system architecture is shown in Figure 3 and Table 6 shows functions and features of installed equipment. The remote microgrid on the test island is an inverter-based small power system. 
Usually, just one Grid Forming Inverter (GFI) controls the system voltage (V) and frequency (f) of Remote microgrid. The \#2 inverter is for backup (if there is a fault at \#1) or vice versa. It means that two GFIs don't operate in parallel because each GFI will control voltage \& frequency and there be voltage oscillation called "hunting" [26].

Table 5. Simulation Results for Design Target.

\begin{tabular}{ccc}
\hline Contents & Quantity & Value \\
\hline PV & Rated Capacity & $314 \mathrm{~kW}$ \\
& Total Production & $355,124 \mathrm{kWh} /$ year \\
& Mean Output & $40.5 \mathrm{~kW}$ \\
& Capacity Factor & $12.90 \%$ \\
& Penetration Rate & $26.30 \%$ \\
\hline Rated Capacity & $100 \mathrm{~kW} \times 4$ ea \\
TT & Total Production & $733,790 \mathrm{kWh} /$ year \\
& Mean Output & $83.7 \mathrm{~kW}$ \\
& Capacity Factor & $20.90 \%$ \\
& Penetration Rate & $54.40 \%$ \\
\hline Rated Capacity & $100 \mathrm{~kW} \times 3 \mathrm{ea}$ \\
Tiesel Generator & Metal Production & $260,207 \mathrm{kWh} /$ year \\
& Mean Output & $137.8 \mathrm{~kW}$ \\
& Fuel Consumption & $78,927 \mathrm{~L} /$ year \\
& Hours of Operation & $1888 \mathrm{~h} /$ year \\
Penetration Rate & $19.30 \%$ \\
\hline Energy Flows & Energy In & $346,597 \mathrm{kWh} /$ year \\
& Energy Out & $328,682 \mathrm{kWh} /$ year \\
& Losses & $17,915 \mathrm{kWh} /$ year \\
\hline & Load & $989,878 \mathrm{kWh} /$ year \\
& Production & $1,349,120 \mathrm{kWh} /$ year \\
& Excess Electricity & $318,316 \mathrm{kWh} /$ year \\
& Renewable Fraction & $73.70 \%$ \\
\hline
\end{tabular}

If the output power from WTs/PVs is bigger than the amount of load, GFI will charge the battery to maintain V\&F. On the contrary, the GFI will discharge the electrical power from the battery to the load. If the surplus power is bigger than the GFI's rated power $(500 \mathrm{kVA})$, the \#3 inverter $(250 \mathrm{kVA})$ will be operated automatically.

Sometimes, the diesel generators are interconnected to the GFI to charge the battery or to supply the power to the loads. We used the previously installed diesel generators to operate in parallel with the GFI without any functional modification. Because each diesel generators can operate in parallel with each other with its droop function. Voltage droop is the intentional loss in output voltage from a device as it drives a load [28]. Frequency droop allows synchronous generators to run in parallel, so that loads are shared among generators in proportion to their power rating [28]. In our test island, GFI will control system voltage $\&$ frequency and diesel generators will be operated in droop mode, so there is no concern for the voltage oscillation problem. WTs \& PVs don't run without GFI, because the diesel 
generators cannot control the frequency properly if there is too much power from WTs \& PVs. In this system, we impose the spinning reserve at the GFI because this system is the inverter-based remote microgrid. Through this, we can reduce the fuel consumption for the spinning reserve of the diesel generators.

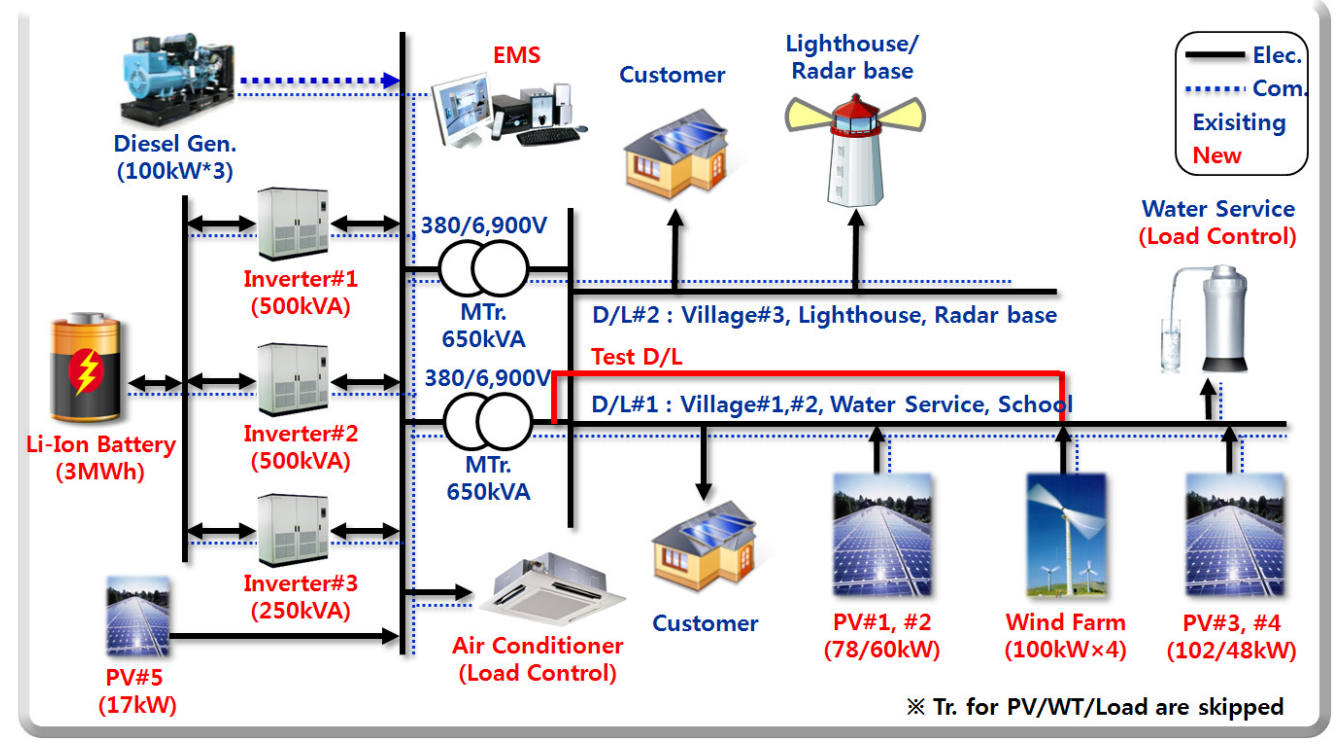

Figure 3. System architecture of the test island.

Test D/L is for the initial system test using GFI, WTs, PVs and load simulator, so normally Test $\mathrm{D} / \mathrm{L}$ is not charged.

Table 6. Functions and Features of Installed Equipment.

\begin{tabular}{|c|c|c|}
\hline Contents & Specification & Functions and Features \\
\hline Energy Manage System & SCADA + Application & $\begin{array}{l}\text { Battery SOC management, Forecasting of load and } \\
\text { renewable energy, Direct load control, Automation }\end{array}$ \\
\hline Grid Forming Inverter & $500 \mathrm{kVA} \times 2,250 \mathrm{kVA} \times 1$ & $\begin{array}{c}\text { Frequency \&voltage control, P/Q control } \\
500 \mathrm{kVA} \# 2 \text { : Backup, } 250 \mathrm{kVA} \text { : for shortage of rating }\end{array}$ \\
\hline Battery & $3 \mathrm{MWh}$, Li-ion & $\begin{array}{l}\text { Electrical energy storage, } 1 \mathrm{C} \text {-rate, NMC type } \\
\text { Three GFIs are connected to } 3 \mathrm{MWh} \text { in parallel }\end{array}$ \\
\hline WT & $100 \mathrm{~kW} \times 4$ & $\begin{array}{l}\text { Permanent Magnet Synchronous Generator } \\
\text { (PMSG) + Full converter, Power limitation, } \\
\text { Power factor \& Voltage control, LVRT, FRT }\end{array}$ \\
\hline PV & 314 kW (8 ea) & $\begin{array}{l}\text { Power limitation, Monitoring of each module, } \\
\text { Water floating PV system for limited site }\end{array}$ \\
\hline Diesel Generator & $100 \mathrm{~kW} \times 3$ & Droop control, Remote on/off \\
\hline Load & $\begin{array}{l}\text { Water pump, Air } \\
\text { conditioner }\end{array}$ & $\begin{array}{l}\text { Water tank is used to energy storage. } \\
\text { Battery room temperature control using surplus energy }\end{array}$ \\
\hline
\end{tabular}

Notes: LVRT: Low Voltage Ride Through, FRT: Fault Ride Through.

In the test island, a water supply tank was installed on a mountainside and water was supplied to households via natural water pressure. Thus, the water level in the water supply tank should be $70 \%$ or higher at all times; the water level was maintained by a water supply motor. If excess power in the 
renewable energy was used for charging the battery, the excess power was used to run the motor via the EMS for water pumping in advance instead of battery charging. In this way, the battery charging could be minimized to extend the battery life. Figures 4-7 are the installed equipment in the test island.

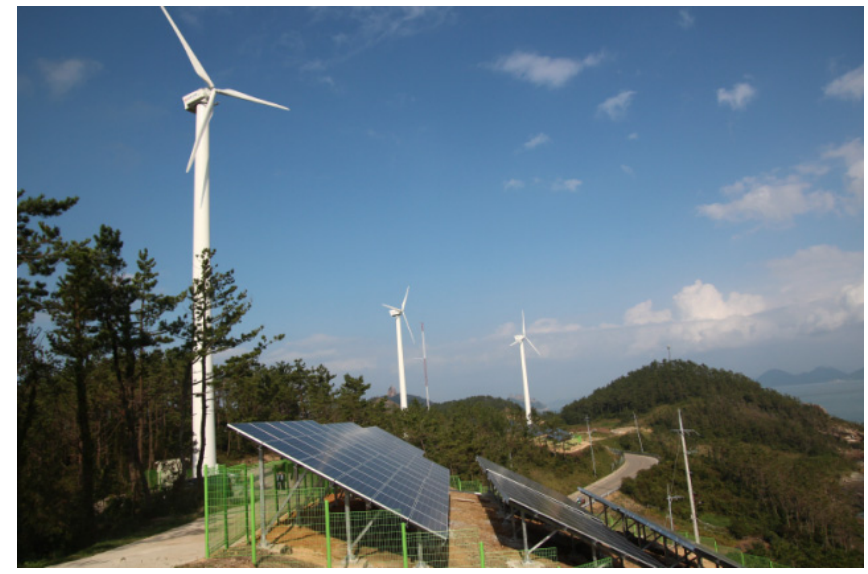

Figure 4. Wind and solar farm.

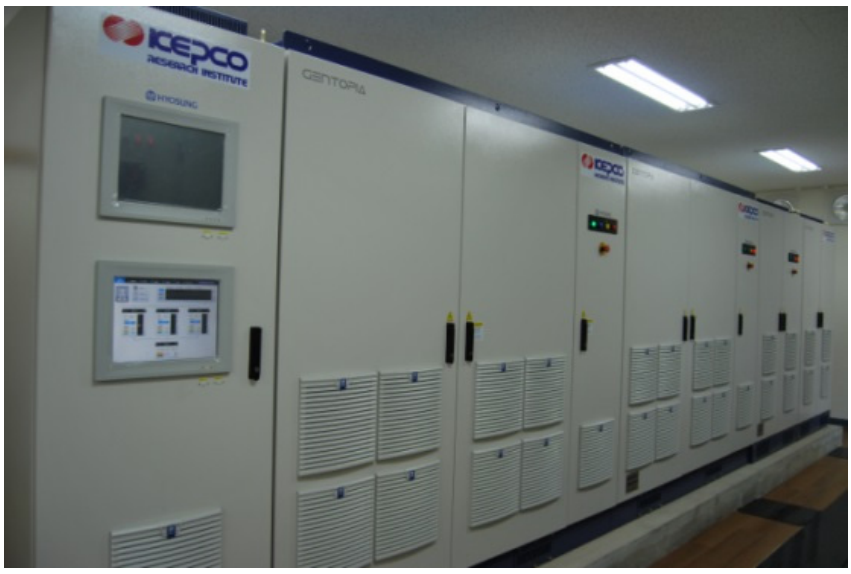

Figure 5. Grid forming inverters.

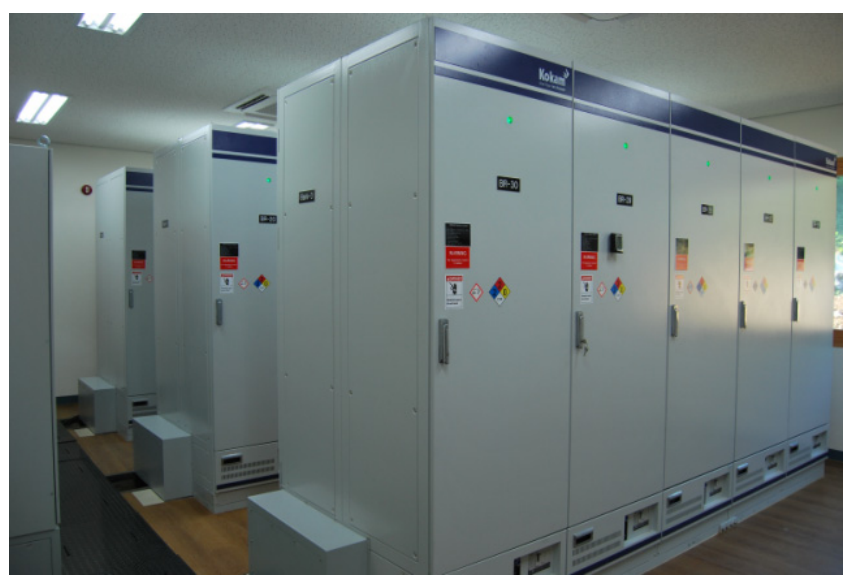

Figure 6. Li-ion battery. 


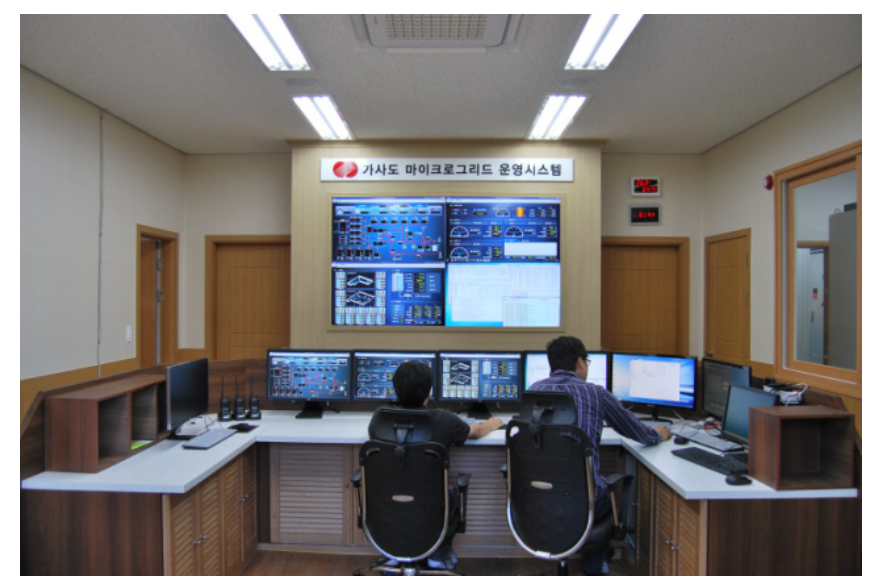

Figure 7. Energy management system.

\subsection{Analysis of Operation Results}

Table 7 shows the operation results from October 2014 to March 2015 after the construction of the remote microgrid. On the test island, wind velocity was high and solar radiation was low in the winter season, whereas wind velocity was low and solar radiation was high in the summer season. The commercial operation of the remote microgrid began in October 2014. Because the WT capacity was greater than the PV capacity, power generation via WT was more than that of PV. During a six-month period, the average renewable energy fraction was approximately $82 \%$ and diesel generator fuel consumption was reduced by $80 \%$.

Figure 8 shows a graph of the frequency comparison between the remote microgrid and the diesel power plant. The frequency-maintaining standard in South Korea is 59.8 to $60.2 \mathrm{~Hz}$ as an average value of a $30 \mathrm{~min}$ interval, which is displayed in the figure as a red dotted line. When supplying power with the diesel generator (green color solid line), the maintenance rate was $57 \%$ as the average value of a $0.2 \mathrm{~s}$ interval. However, when supplying power with the remote microgrid (blue solid line), the maintenance rate was $100 \%$ as the average value of a $0.2 \mathrm{~s}$ interval. That is, the power quality of the remote microgrid was better than that of the diesel power plant, despite the high renewable energy rate.

Table 7. Energy production and load of the test island after commission.

\begin{tabular}{ccccccccc}
\hline Generator & Unit & October & November & December & January & February & March & Average \\
\hline Wind Turbine & $\mathrm{kWh}$ & 33,301 & 42,107 & 56,577 & 55,700 & 50,200 & 31,400 & 44,881 \\
Photovoltaic & $\mathrm{kWh}$ & 27,659 & 23,537 & 15,005 & 21,064 & 23,705 & 35,940 & 24,485 \\
$\begin{array}{c}\text { Diesel Generator } \\
\text { Total Production }\end{array}$ & $\mathrm{kWh}$ & 20,300 & 16,839 & 21,061 & 12,672 & 6222 & 13,539 & 15,106 \\
$\begin{array}{c}\text { (=Load and Loss) } \\
\text { Renewable Fraction }\end{array}$ & $\mathrm{kWh}$ & 81,260 & 82,483 & 92,643 & 89,436 & 80,127 & 80,879 & 84,471 \\
$\begin{array}{c}\text { Fuel Consumption } \\
\text { (after commission) }\end{array}$ & $\mathrm{Liter}$ & $\mathbf{6 3 7 9}$ & 5272 & 6049 & 3703 & 1699 & 3600 & 4450 \\
$\begin{array}{c}\text { Fuel Consumption } \\
\text { (before commission) }\end{array}$ & $\mathrm{Liter}$ & 21,828 & 21,829 & 21,830 & 24,836 & 19,998 & 23,611 & 22,322 \\
\hline
\end{tabular}




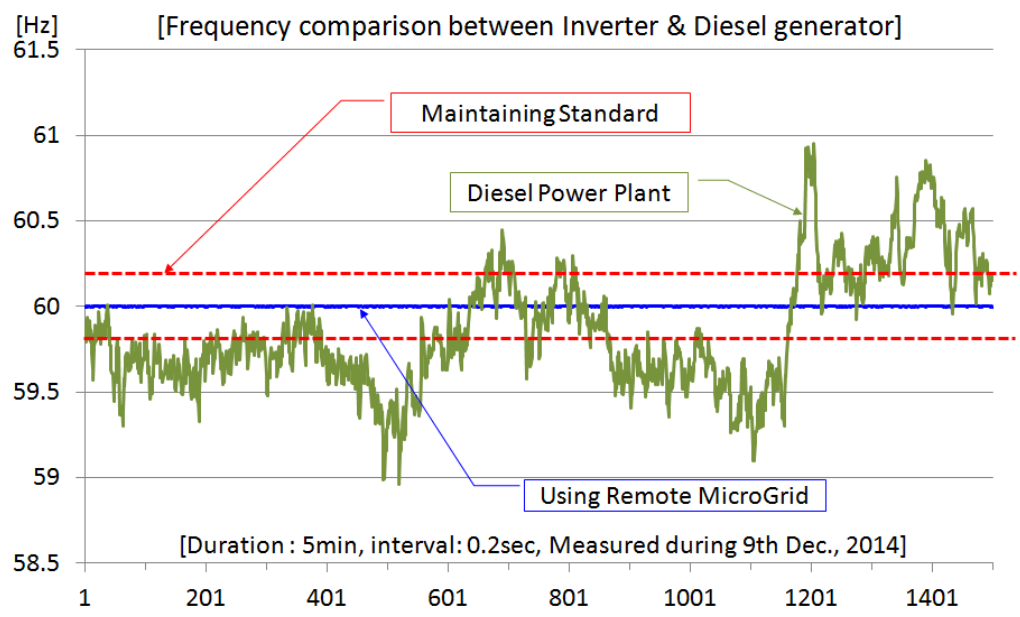

Figure 8. Frequency comparison between the remote microgrid and diesel power plant.

\subsection{Operation Results Comparison with Economic Feasibility Study}

Table 8 shows the expected energy production and load on the test island according to HOMER. The average load was $84,650 \mathrm{kWh}$, which was similar to that of $84,471 \mathrm{kWh}$ in Table 5 . That is, the loads were relatively well simulated. The power generation results via PV were 26,750 and 24,485 $\mathrm{kWh}$, respectively, which showed an approximately $8.5 \%$ error, which was not significantly different compared to the expected power generation. However, the average WT power generation results were 96,987 and 44,881 kWh, respectively, which showed a difference by more than two-fold. This result was due to the significant WT power generation in the winter caused by high wind velocity; moreover, the battery was fully charged, thereby often stopping WT or enforcing output restriction. Another key reason for the error was the lower average wind velocity than in past years and several line fault accidents.

Table 8. Expected energy production and load of the test island by HOMER.

\begin{tabular}{ccccccccc}
\hline Generator & Unit & October & November & December & January & February & March & Average \\
\hline Wind Turbine & $\mathrm{kWh}$ & 67,760 & 71,989 & 146,867 & 123,287 & 83,624 & 88,398 & 96,987 \\
Photovoltaic & $\mathrm{kWh}$ & 32,788 & 21,948 & 20,403 & 23,634 & 25,319 & 36,411 & 26,750 \\
Diesel Generator & $\mathrm{kWh}$ & 16,988 & 20,411 & 8143 & 5894 & 12,964 & 4965 & 11,561 \\
Total Production & $\mathrm{kWh}$ & 117,536 & 114,347 & 175,413 & 152,815 & 121,907 & 129,773 & 135,299 \\
Total Load Served & $\mathrm{kWh}$ & 81,563 & 81,901 & 85,719 & 87,700 & 82,580 & 88,437 & 84,650 \\
Renewable Fraction & $\%$ & 85.5 & 82.2 & 95.4 & 96.1 & 89.4 & 96.2 & 91.0 \\
Fuel Consumption & $\mathrm{Liter}$ & 5124 & 6115 & 2462 & 1782 & 3911 & 1485 & 3480 \\
Excess Energy and Loss & $\mathrm{kWh}$ & 35,973 & 32,446 & 89,694 & 65,115 & 39,327 & 41,336 & 50,649 \\
\hline
\end{tabular}

Accordingly, the average renewable fraction was also low at approximately $82 \%$, which was unlike the initial expectation. Moreover, the average fuel consumption was also increased from 3480 to $4450 \mathrm{~L}$. The average fuel consumption was reduced by $81 \%$ compared to that of the previous year.

\subsection{Efficient Operation of Diesel Generators in the Remote Microgrid}

If power is supplied to loads using only a diesel generator, the diesel generator would be entirely responsible for frequency control due to invariant loads. Under this circumstance, a fuel input amount 
can suddenly vary according to invariant loads so that fuel efficiency can be degraded. If a diesel generator is run in parallel with a grid forming inverter (GFI), the GFI handles frequency control due to invariant loads. Accordingly, the diesel generator can be run with constant output as well as improved fuel efficiency. Because parallel operation of two generators is not needed for reserve power, the diesel generator can be run in the highest efficiency region.

Table 9 shows a comparison of power generation efficiency between a power supply using only a diesel generator and a power supply using a diesel generator running in parallel with the GFI. This is the result of fuel consumption and power generation when real loads were supplied for $24 \mathrm{~h}$ each. According to data in Table 9, efficiency was improved by $14.2 \%$. Operation efficiency of the inverter is normally $88 \%$ to $95 \%$, and round-trip efficiency of the battery is $90 \%$ to $95 \%$. Thus, when a diesel generator is run in the remote microgrid, it should be run in the highest efficiency section. The maximum output of the diesel generator should also not exceed the load to prevent a power loss due to charging and discharging of the battery. This would result in improvements in the overall system efficiency.

Table 9. Fuel consumption comparison of a diesel generator.

\begin{tabular}{cccc}
\hline \multirow{2}{*}{ Operation Type } & At Diesel Power Plant & & At Remote Microgrid \\
\cline { 2 - 2 } Fuel Consumption & 2 gen-set in parallel & & one gen-set with grid forming inverter (GFI) \\
\hline Total Production & $766.2 \mathrm{~L} / 24 \mathrm{~h}$ & & $562.7 \mathrm{~L} / 24 \mathrm{~h}$ \\
Average Power & $2319.3 \mathrm{kWh}$ & & $1946.2 \mathrm{kWh}$ \\
Energy per Fuel & $96.6 \mathrm{~kW}$ & $81 \mathrm{~kW}$ \\
Fuel per Energy & $3.02 \mathrm{kWh} / \mathrm{L}$ & & $3.45 \mathrm{kWh} / \mathrm{L}$ \\
\hline
\end{tabular}

\section{Conclusions}

In this paper, we presented a constructed energy independent island on a test island in South Korea using remote microgrid technology. We presented the operation results from a six-month period study. To construct a remote microgrid, an economic feasibility study was conducted, and the results were presented. The system structure required for reliably testing and operating the developed system was described. The power generation produced from the developed generators and predicted power generation using HOMER were compared. Loads and predicted results of PV had similar outputs with those of the real system. However, WT and diesel power generation showed a large difference, which was due to frequent stops of WT due to high wind velocity on the test island in the winter season. The power quality of the remote microgrid was also improved more than that of the diesel generator. When a diesel generator is run in the remote microgrid, it should be run in the highest efficiency section and the maximum output should not exceed the load to prevent a power loss.

\section{Future Work and Contributions}

Based on the analysis results to date, we will examine how to utilize excess power in the winter season. The commercial operation of the developed remote microgrid will continue. The demonstration results for one year or longer will be compared with HOMER simulation results. Furthermore, we are 
developing an EMS to efficiently run the remote microgrid and we will present the demonstration results. This paper contributed to the production of more accurate simulation results from economic feasibility studies for remote microgrids than previous studies. In addition, information in this study is expected to reduce trials and errors in real sites in when remote microgrid technology is implemented in the future.

\section{Acknowledgments}

This work was supported by Korea Institute of Energy Technology Evaluation and Planning (KETEP) grant funded by Korea government Ministry of Knowledge Economy (No. 20123010020080).

\section{Author Contributions}

W.-K.C and H.-J.L conceived and designed the experiments; W.-K.C and J.-N.W performed the simulation and the experiments; J.-S.P analyzed the data; W.-K.C and J.-E.K wrote the paper.

\section{Conflicts of Interest}

The authors declare no conflict of interest.

\section{Appendix. Input Data for Economic Feasibility Study}

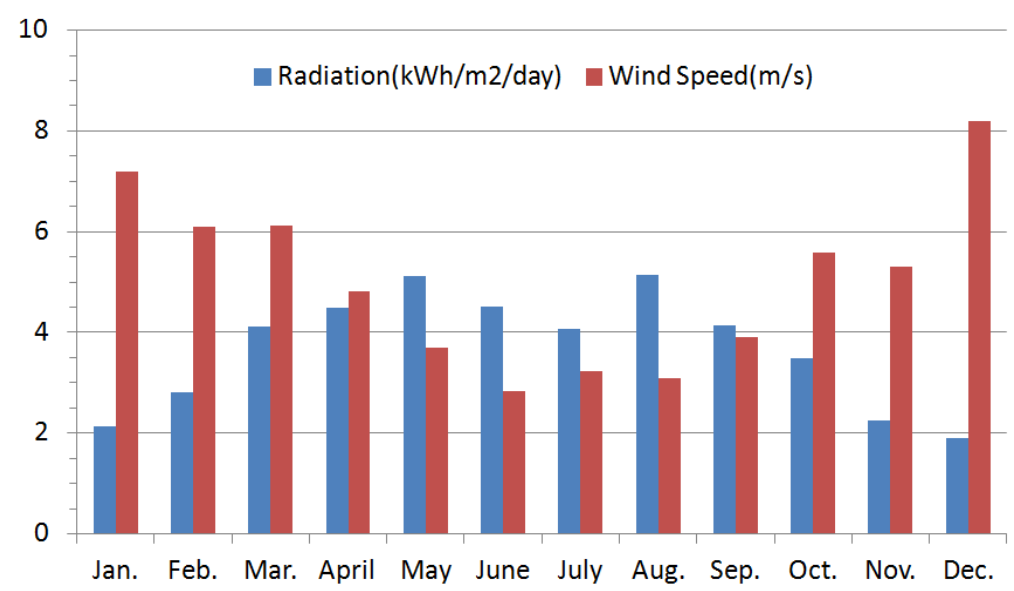

Figure A1. Weather Data of Test Island [26].

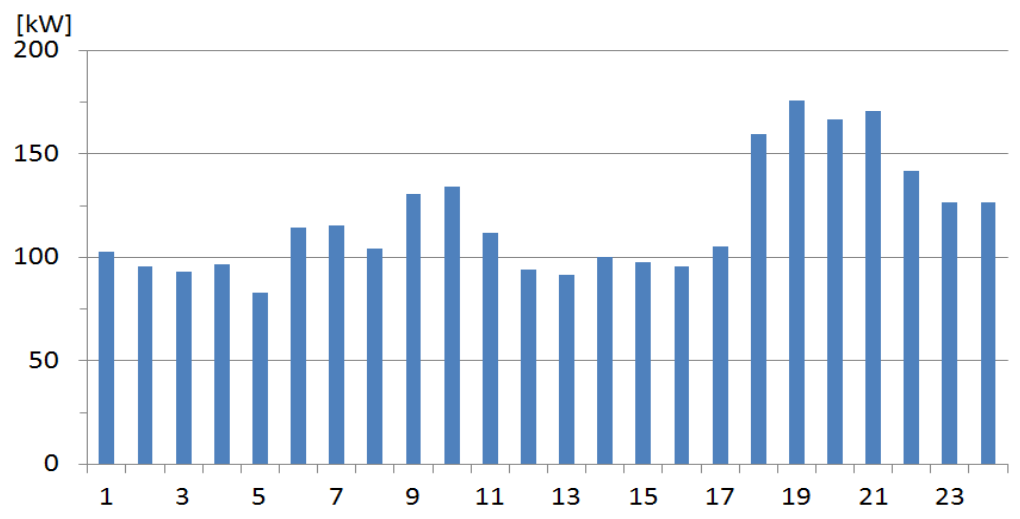

Figure A2. Daily Load Profile of Test Island (January) [26]. 


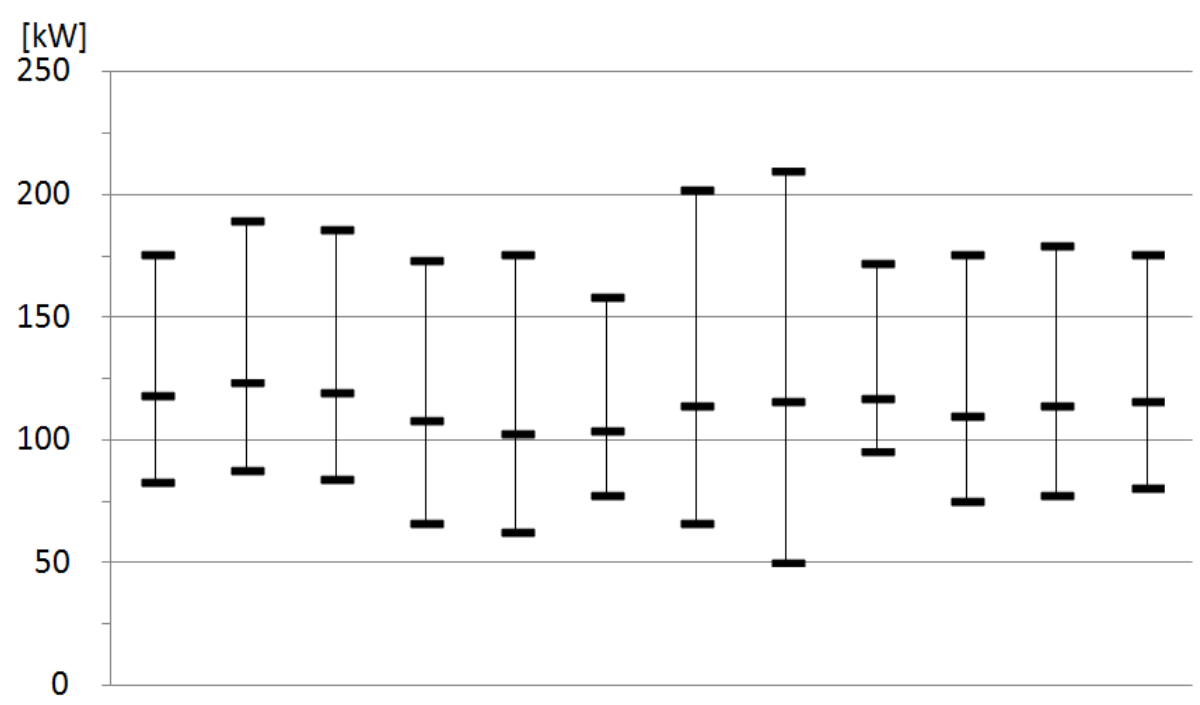

Jan. Feb. Mar. April May June July Aug. Sep. Oct. Nov. Dec.

Figure A3. Annual Load Profile of Test Island (2013) [26].

Table A1. Economic Feasibility Study Input Data [26].

\begin{tabular}{ccc}
\hline Contents & Item & Value \\
\hline \multirow{3}{*}{ PV } & Capital & $3200 \$ / \mathrm{kW}$ \\
& O\&M & $300 \$ / \mathrm{kW}$ \\
& Life Time & 20 years \\
\hline \multirow{2}{*}{ WT } & Capital & $550,000 \$ / 100 \mathrm{~kW}$ \\
& O\&M & $6000 \$ / 100 \mathrm{~kW}$ \\
& Life Time & 20 years \\
\hline \multirow{3}{*}{ Inverter } & Capital & $280,000 \$ / 500 \mathrm{kVA}$ \\
& O\&M & $4000 \$ / 500 \mathrm{kVA}$ \\
& Life Time & 20 years \\
\hline \multirow{3}{*}{ Battery } & Capital & $63,000 \$ / 100 \mathrm{kWh}$ \\
& Replacement Cost & $38,000 \$ / 100 \mathrm{kWh}$ \\
& O\&M & $600 \$ / 100 \mathrm{kWh}$ \\
& Life Time & 10 years \\
\hline \multirow{2}{*}{ Gen-set } & Capital & Existing \\
& O\&M & $5.5 \$ \mathrm{~h} / 100 \mathrm{~kW}$ \\
& Life Time & $175,200 \mathrm{~h} / 100 \mathrm{~kW}$ \\
\hline \multirow{2}{*}{ Economics } & Interest rate & $5 \%$ \\
& Project Lifetime & 20 years \\
& Fixed O\&M Cost & $386,000 \$ /$ year \\
\hline
\end{tabular}

\section{References}

1. Fay, G.; Schwoerer, T.; Keith, K. Alaska Isolated Wind-Diesel Systems: Performance and Economic Analysis; University of Alaska Anchorage: Alaska, AK, USA, 2010. 
2. Chae, W.K.; Lee, H.J.; Hwang, S.W.; Song, I.K.; Kim, J.E. Isolated microgrid's voltage and frequency characteristic with induction generator based wind turbine. Smart Grid Renew. Energy 2014, 5, 180-192.

3. Martinez-Cid, R.; O’Neill-Carrillo, E. Sustainable Microgrids for Isolated Systems. In Proceedings of the Transmission and Distribution Conference and Exposition, New Orleans, LA, USA, 19-22 April 2010; pp. 1-7.

4. Muljadi, E.; McKenna, H.E. Power Quality Issues in a Hybrid Power System. In Proceedings of the Thirty-Sixth IAS Annual Meeting, Conference Record of the Industry Applications Conference, Chicago, IL, USA, 30 September-4 October 2001.

5. Senjyu, T.; Nakaji, T.; Uezato, K.; Funabashi, T. A hybrid power system using alternative energy facilities in isolated island. IEEE Trans. Energy Convers. 2005, 20, 406-414.

6. Li, J.; Wei, W.; Xiang, J. A simple sizing algorithm for stand-alone PV/wind/battery hybrid microgrids. Energies 2012, 5, 5307-5323.

7. Liang, H.; Zhuang, W. Stochastic modeling and optimization in a microgrid: A survey. Energies 2014, 7, 2027-2050.

8. Wang, J.; Yang, F. Optimal capacity allocation of standalone wind/solar/battery hybrid power system based on improved particle swarm optimisation algorithm. IET Renew. Power Gener. 2013, 7, 443-448.

9. Bansal, A.K.; Kumar, R.; Gupta, R.A. Economic analysis and power management of a small autonomous hybrid power system (SAHPS) using biogeography based optimization (BBO) algorithm. IEEE Trans. Smart Grid 2013, 4, 638-648.

10. Wies, R.W.; Johnson, R.; Agrawal, A.N.; Chubb, T.J. Simulink model for economic analysis and environmental impacts of a PV with diesel-battery system for remote villages. IEEE Trans. Power Syst. 2005, 20, 692-700.

11. Xu, L.; Ruan, X.; Mao, C.; Zhang, B.; Luo, Y. An improved optimal sizing method for wind-solar-battery hybrid power system. IEEE Trans. Sustain. Energy 2013, 4, 774-785.

12. Stiel, A.; Skyllas-Kazacos, M. Feasibility study of energy storage systems in wind/diesel applications using the HOMER model. Appl. Sci. 2012, 2, 726-737.

13. Yoo, K.; Park, E.; Kim, H.; Ohm, J.Y.; Yang, T.; Kim, K.J.; Chang, H.J.; del Pobil, A.P. Optimized renewable and sustainable electricity generation systems for Ulleungdo Island in South Korea. Sustainability 2014, 6, 7883-7893.

14. Purser, M.S. A Technical and Economic Feasibility Study of Implementing a Microgrid at Georgia Southern University. Master's Thesis, Georgia Southern University, Statesboro, GA, USA, May 2014.

15. Mizani, S.; Yazdani, A. Optimal Design and Operation of a Grid-Connected Microgrid. In Proceedings of the Electrical Power and Energy Conference (EPEC), Montreal, QC, Canada, 22-23 October 2009.

16. Fan, Y.; Rimali, V.; Tang, M.; Nayar, C. Design and Implementation of Stand-alone Smart Grid Employing Renewable Energy Resources on Pulau Ubin Island of Singapore. In Proceedings of the 2012 Asia-Pacific Symposium on Electromagnetic Compatibility (APEMC), Singapore, 21-24 May 2012; pp. 441-444.

17. Kojima, T.; Fukuya, Y. Microgrid system for isolated islands. Fuji Electric Rev. 2011, 57, 125-130. 
18. Prull, D.S. Design and Integration of an Isolated Microgrid with a High Penetration of Renewable Generation. Ph.D. Thesis, University of California, Berkeley, CA, USA, May 2008.

19. Kaldellis, J.K.; Kavadias, K.A. Cost-benefit analysis of remote hybrid wind-diesel power stations: case study Aegean Sea islands. Energy Policy 2007, 35, 1525-1538.

20. Ulleberg, Ø.; Rinnan, A. Renewable Energy System Concepts for Nolsoy, the Faeore Islands; Institute for Energy Technology: Haden, Norway, 2006.

21. Ackermann, T. Wind Power in Power Systems; John Wiley \& Sons: Hoboken, NJ, USA, 2005.

22. Baring-Gould, I.; Dabo, M. Technology, Performance, and Market Report of Wind-Diesel Applications for Remote and Island Communities. In Proceedings of the WINDPOWER 2009 Conference and Exhibition, Chicago, IL, USA, 4-7 May 2009.

23. KEPCO (Korea Electric Power Corporation). Report for the Prime Cost Report of Diesel Power Plant; KEPCO: Seoul, Korea, 2012.

24. Brett, P. A New Isolated Grid Paradigm. In International Wind-Diesel Workshop; US Department of Energy: Alaska, AK, USA, 2011.

25. HOMER. Available online: http://www.homerenergy.com (accessed on 13 May 2015).

26. KEPRI (Korea Electric Power Research Institute). 2nd Year Report for Development of Convergence and Integration Technology for Renewable-Based Energy System and Its Grid Interconnection; KEPCO (Korea Electric Power Corporation): Daejeon, Korea, 2014.

27. Report for Operation Results for the Diesel Power Plant for Gasado; Jindo-Gun (Local Government of Korea): Jindo-Gun, Korea, 2014.

28. Chowdhury, S.; Chowdhury, S.P.; Crossley, P. Microgrids and Active Distribution Networks; The Institution of Engineering and Technology: Herts, UK, 2009.

(C) 2015 by the authors; licensee MDPI, Basel, Switzerland. This article is an open access article distributed under the terms and conditions of the Creative Commons Attribution license (http://creativecommons.org/licenses/by/4.0/). 